Int. J. Electrochem. Sci., 13 (2018) 6015 - 6026

\title{
Influence of EDTA/THPED Dual-Ligand on Copper Electroless Deposition
}

\author{
Lu Jianhong ${ }^{1,2}$, Jimmy Yun $^{2,3}$,Lei Haiping ${ }^{1}$, Tu Jiguo ${ }^{1}$, Jiao Shu-qiang ${ }^{1, *}$ \\ ${ }^{1}$ State Key Laboratory of Advanced Metallurgy, University of Science and Technology Beijing, \\ Beijing 100083, China \\ ${ }^{2}$ Changzhou Institutes of Advanced Materials, Beijing University of Chemical Technology, \\ Changzhou 213164, China \\ ${ }^{3}$ School of Chemical and Pharmaceutical Engineering, Hebei University of Science and Technology, \\ Shijiazhuang 050018, China \\ *E-mail: sjiao@ustb.edu.cn
}

doi: $10.20964 / 2018.06 .24$

Received: 26 January 2018 / Accepted: 2 March 2018 / Published: 10 May 2018

Single ligand electroless plating process has been studied extensively in the past decades, this study investigates the advantages of using a dual ligand system (EDTA/THPED) on electroless plating process. Electrochemistry techniques including mixed potential and linear sweep voltammetry (LSV) are used to examine the fundamental deposition mechanism of dual ligand system, providing critical information for dual ligand formulation design. Mixed potential tests indicated that increasing the Tetrakis (2-hydroxypropyl) ethylenediamine (THPED) concentration negatively shifts the electrode potential. The overall process was divided into three regions: induction, transition and stability. The degree of potential negatively shifted at each region was related to absorption, the type of redox reaction, ion diffusion and migration. Electrochemical analyses showed that there was an obvious peak for all anodic and cathodic reactions, respectively at around $-0.42 \mathrm{~V}$ and $-0.57 \mathrm{~V}$, whereby the current density depended on the THPED concentration. Moreover LSV study demonstrated control factor of autocatalytic reactions is cathodic reduction process of copper ion. The electroless deposition rate results were also in good agreement with mixed potential and electrochemical measurements, and the copper deposition rate increased significantly with the addition of THPED, and showed parabolic growth pattern. Metallographic studies of the dual-ligand electroless copper deposits revealed that their topographic structures had uniform and fine particle distribution, and a high-purity product without $\mathrm{Cu}_{2} \mathrm{O}$ inclusions was detected. Copper layers displayed that the addition of THPED favored the formation of the preferred orientation on the (220) lattice plane.

Keywords: Electroless copper; Ligand; Mixed potential 
(C) 2018 The Authors. Published by ESG (www.electrochemsci.org). This article is an open access article distributed under the terms and conditions of the Creative Commons Attribution license (http://creativecommons.org/licenses/by/4.0/). 